\title{
Correction to: Framework Conditions, Innovation and Productivity in European Regions
}

\section{Debora Revoltella $^{1} \cdot$ Andrea Brasili $^{1}$ (D) $\cdot$ Rocco L. Bubbico $^{1} \cdot$ Annamária Tüske $^{1}$. Christoph Weiss ${ }^{1}$}

Published online: 11 June 2019

(c) Association for Comparative Economic Studies 2019

\section{Correction to: Comparative Economic Studies https://doi.org/10.1057/s41294-019-00091-2}

Unfortunately, figure 7 was displayed incorrectly. Correct Fig. 7 is shown here. The original article has been corrected.

The original article can be found online at https://doi.org/10.1057/s41294-019-00091-2.

Andrea Brasili a.brasili@eib.org

1 Economics Department, European Investment Bank, Luxembourg, Luxembourg 

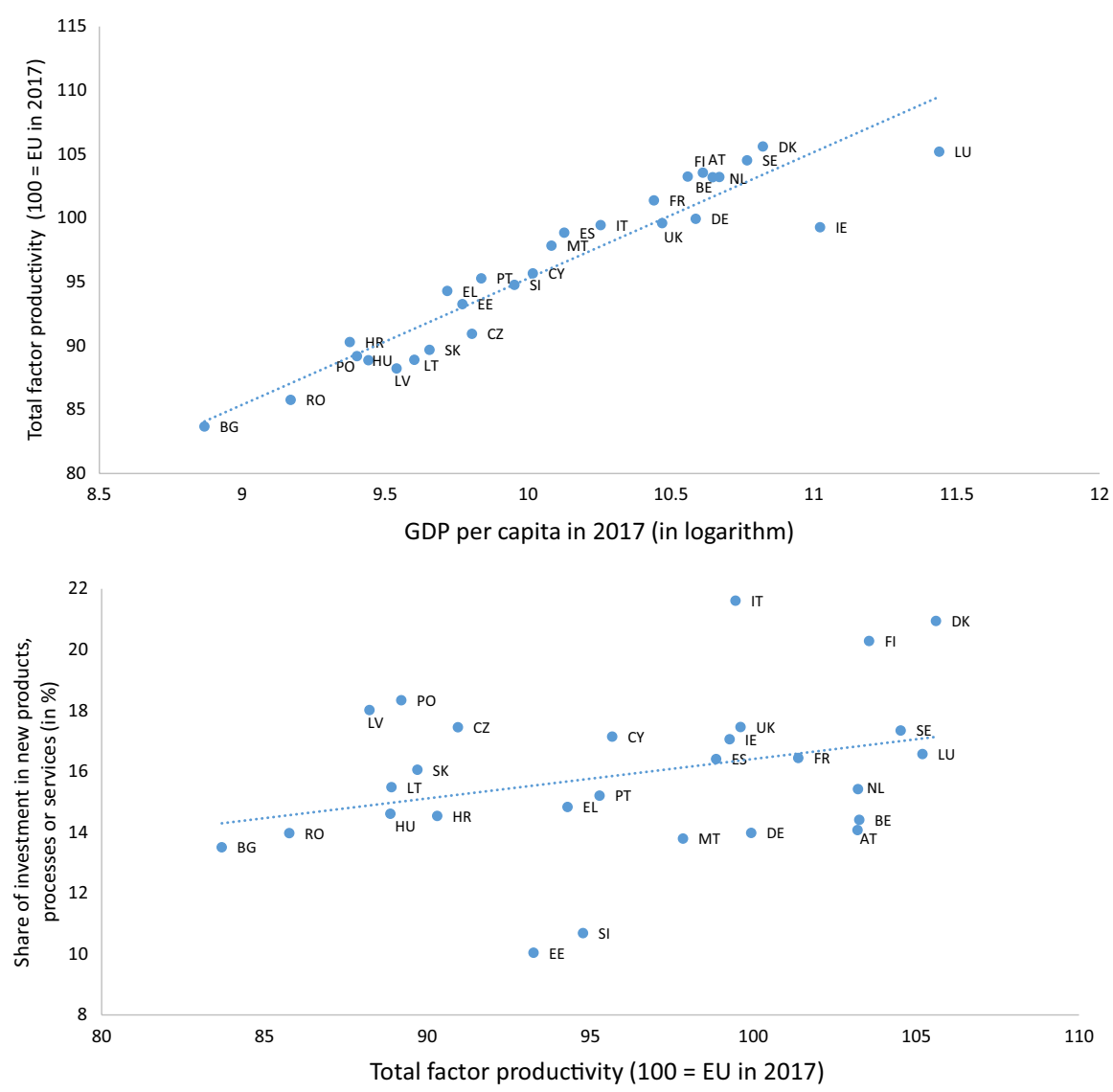

Fig. 7 GDP per capita, total factor productivity and investment in new products, processes or services at the country level. Note Data on all firms are pooled from the three waves of EIBIS (waves 2016, 2017 and 2018) to construct an average of total factor productivity for each country. Firms in EIBIS are weighted with value added. Source: Authors' calculations based on Eurostat and EIB Investment Survey (EIBIS)

Publisher's Note Springer Nature remains neutral with regard to jurisdictional claims in published maps and institutional affiliations. 